\title{
ВЛИЯНИЕ ПСИХОТРАВМЫ РАЗВОДА НА ИЗМЕНЕНИЕ ЖИЗНЕННОЙ ПЕРСПЕКТИВЫ ЛИЧНОСТИ
}

\section{INFLUENCE OF PSYCHOTRAIN IN A SCAN OF CHANGE ON CHANGING THE PERSONALITY OF A PERSONALITY}

V. Makhov

Summary: The article is devoted to the analysis of the results of the study of the influence of divorce trauma on the change in the temporal perspective of a person. The features of changing the time perspective under the influence of divorce and the role of the emotional sphere in the distortion of the time perspective are revealed. Attention is focused on the possibility of diagnosing latent mental trauma in psychotherapeutic practice based on client assessments of their time perspective.

Keywords: psychological trauma, divorce, time perspective, positive affect, negative affect, negative past, hedonistic present, fatalistic present.

\section{Введение}

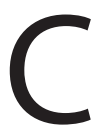

овременная жизнь характеризуется условиями постоянного стресса и наличием психотравмирующих ситуаций. Ускорение технического прогресса, постоянная погоня за материальными благами, увеличение разрыва между богатыми и бедными слоями населения, которая приводит к несоответствию желаемого и действительного - все эти факторы влекут за собой возникновение психотравм самой различной природы. Психотравму, таким образом, можно определить, как жизненное событие или ситуацию, которая не только оказывает влияние на самые значимые стороны существования человека, но и приводит его к глубокому и длительному переживанию.

Среди различных психотравмирующих ситуаций следует выделить особый тип психотравмы - «психотравму развода», связанную с распадом брачно-семейных отношений. В отличие от многих психотравмирующих ситуаций, например, таких как стихийные бедствия, насильственные преступления и т.п., психотравма развода, как правило, не наступает неожиданно. Обычно ей предшествует длительный процесс «охлаждения» отношений между супругами, ссоры и конфликты.

Переживания развода во многом схожи с переживанием непоправимой потери, которая проходит следующие стадии:

1. Стадия шока. Она может протекать по-разному: слезы, ступор, растерянность, любые негативные эмоциональные реакции. Может длиться до не-
Махов Виталий Андреевич

ФГБОУ «Тольяттинский государственный университет» dr.mahov@yandex.ru

Аннотация: Статья посвящена анализу результатов исследования влияния психотравмы развода на изменение временной перспективы личности. Выявлены особенности изменения временной перспективы под влиянием развода и роль эмоциональной сферы в искажении временной перспективы. Акцентируется внимание на возможности диагностики латентной психической травмы в психотерапевтической практике на основе оценок клиентом своей временной перспективы.

Ключевые слова: психотравма, развод, временная перспектива, позитивный аффект, негативный аффект, негативное прошлое, гедонистическое настоящее, фаталистическое настоящее.

скольких дней.

2. Стадия гнева. Это период взаимных обвинений, скандалов, желания вернуть утраченное. Продолжается от нескольких недель до нескольких месяцев.

3. Стадия самообвинения. Снижается самооценка, проявляется аутоагрессия. Это период возникновения соматических заболеваний: обострение язвы, гипертонии, вегето-сосудистой дистонии, неврологических расстройств. Велика вероятность развития депрессии, поведенческих нарушений. Этот период, когда субъект может впадать в крайности: от гнева к депрессии, от обвинений во всем окружающих до самобичевания. Такое состояние может длиться до нескольких месяцев.

4. Реорганизация жизни. Возникновение новых интересов и целей. адаптация к новой социальной роли.

Возникновение психической травмы развода рассматривается как следствие незавершенности инстинктивной реакции организма на травматическое событие. Внутреннюю психологическую травму можно сравнить, например, с физической раной руки, к которой человек уже давно привык и не обращает на нее никакого внимания. Однако человек переживает очень сильную боль, когда кто-то прикасается к больной руке. Отличительной особенностью психологической травмы от физической травмы является то, что ее последствия также носят психологический характер. Наиболее сильной реакцией на психотравму, как известно является суицид и другие виды аутоагрессивного поведения. Известно, что 
сильное психотравмирующее событие может привести к ощущению, что «жизнь закончилась», «все потеряно», «дальше дороги нет» и т.д. Таким образом, психотравма неизбежно влияет не только на оценку текущих событий, но и на восприятие жизненных перспектив личности, оценку как личного прошлого, так и будущего.

Цель статьи - установить особенности влияния психотравмы развода на восприятие временной перспективы. Согласно гипотезе исследования - психологическая травма развода приводит к изменению временной перспективы личности, которое заключается в ее негативной переоценке.

Методика исследования. В исследовании применялись следующие методики: 1) методика PANAS для оценки позитивного и негативного аффекта, что подтверждает наличие психотравмы; 2) Опросник временной перспективы ZPTI Зимбардо - для оценки временной перспективы личности. В исследовании приняли участие 80 человек, среди которых было 40 мужчин и 40 женщин в возрасте от 26 до 48 лет. Испытуемые были разделены на две группы: 40 чел. - переживших развод (основная группа) и 40 чел. - контрольная группа (состоящие в браке). Продолжительность времени после развода в основной группе составила от 6 месяцев до 5 лет (в среднем 2,4 года). Каждая группа была сбалансирована по полу (одинаковое количество мужчин и женщин), что позволило нивелировать влияние гендерного фактора на оценку временных перспектив личности. Для статистической обработки данных были использованы U-критерий Манна-Уитни и коэффициент корреляции р-Спирмена.

Результаты исследования. В ходе исследования подтвердилось то, что что развод является психотравмирующим событием. Эмоциональная сфера респондентов основной группы характеризуется пониженными показателями позитивного аффекта $(p \leq 0,01)$ и повышенными показателями отрицательного аффекта по сравнению с контрольной группой ( $p \leq 0,05)$.

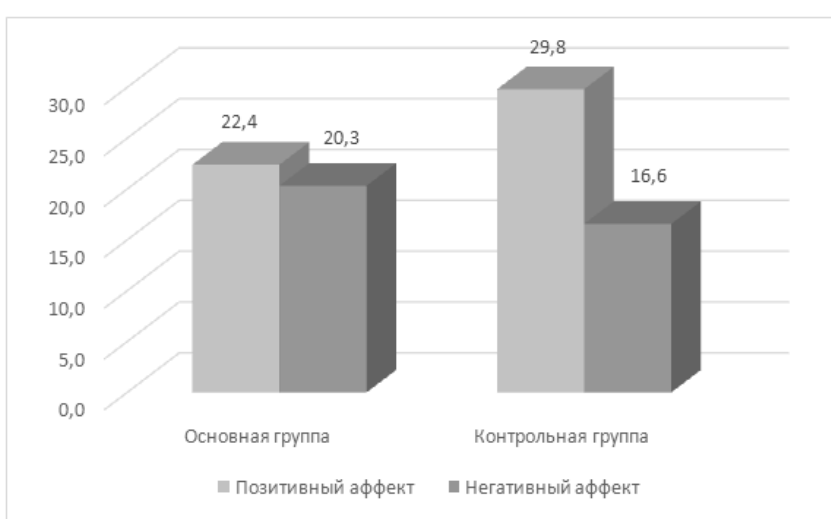

Рис 1. Средние значения шкал методики PANAS в основной и контрольной группах
В отношении временной перспективы по методике Зимбардо было обнаружено, что респонденты основной группы оценивают свое прошлое как более негативное по сравнению с контрольной группой $(p \leq 0,05)$, что подтверждает наличие психологической травмы в прошлом. Также респонденты, пережившие развод склонны к меньшей оценке гедонистического и позитивного настоящего ( $p \leq 0,05)$ и переоценивают свое фаталистическое настоящее ( $p \leq 0,05)$. Однако оценка временной перспективы будущего в основной группе оказалась незначительно выше, чем в контрольной группе, что может быть обусловлено действием психологических защитных механизмов и переносом на будущее планов по созданию семьи, восприятием будущего как более счастливого по сравнению с настоящим.

Разделение группы по половому признаку не позволило установить гендерных различий в отношении оценок временной перспективы, что говорит о том, что развод является психотравмой как для женщин, так и мужчин, хотя его переживание и носит различный характер.

Предположение о том, что психотравма развода оказывает влияние на восприятие временной перспективы была проверена при помощи коэффициента корреля-

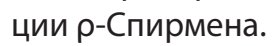

Таблица 1

Коэффициенты корреляции между шкалами методики PANAS и шкалами методики ZPTI Зимбардо

\begin{tabular}{|l|l|l|}
\hline & Позитивный аффект & Негативный аффект \\
\hline Негативное прошлое & $0,366^{*}$ & 0,097 \\
\hline Гедонистическое настоящее & $-0,069$ & $-0,038$ \\
\hline Позитивное прошлое & $-0,194$ & 0,122 \\
\hline Фаталистическое настоящее & 0,194 & $-0,277$ \\
\hline Будущее & $-0,014$ & $-0,015$ \\
\hline
\end{tabular}

* - статистически значимая взаимосвязь на уровне $p \leq 0,05$

Оценка своего прошлого как негативного (по методике ZРTI Зимбардо) положительно связана с позитивным эффектом, измеряемым по методике PANAS, т.е. чем более отрицательное отношение к своему прошлому, тем более выражен позитивный аффект. Такая взаимосвязь может быть интерпретирована как эффект избавления от негативных или даже токсичных супружеских отношений.

В ряде случаев, именно развод между супругами является окончанием длительной психотравмирующей ситуации, однако, это не говорит о том, что психотравма исчезла, особенно, если развод касается не только супругов, но и детей. Дополнительным психотравмирующим фактором расторжение брачно-семейных отно- 
шений является не только не сложившая личная жизнь супругов, но и психологическая травма, которую развод супругов несет другим участникам семейных отношений - детям, родителям супругов и другим родственникам. Члены семьи и друзья также становятся теми, кто переживает травматическое событие, и часто испытывают посттравматические последствия. Таким образом можно говорить о том, что развод несет как прямую, так и косвенную психотравму. С некоторой вероятностью можно утверждать, что психологическая травма оказывает на изменение жизненных перспектив не сразу, а через некоторое время, и влияние психотравмы также сильнее проявляется в будущем. Это может связано с тем, что последствия психотравмы осознаются не сразу, а лишь со временем. В первую очередь негативный аффект развода оказывает сильное влияние на оценку перспектив в семейной сфере снижая стремление к повторному браку. Сильная психологическая травма оказывает влияние на изменение жизненных перспектив изменяя как ценности человека, так и его планы на будущее.

Если рассматривать психотравму с точки зрения психологии здоровья, то можно обнаружить, что она имеет двойную природу: сначала проявляется ее разрушительная сила, она лишает человека способности радоваться жизни. С другой стороны, парадокс психотравмы заключается в том, что она способна трансформировать человека, делать его сильнее и психологически устойчивее по отношению к таким же трудностям. Психика человека имеет свои защитные механизмы, которые позволяют ей сохранить свою целостность и выжить.

Существуют различные взгляды на психотравму и работу с ней. Особого внимания заслуживают два направления работы - это танцевально-двигательная и соматическая психотерапии. Питер Левин, американский ученый и психотерапевт, разработал метод, который назвал «Соматическое переживание». Эта техника применяется для работы как с шоковыми травматическими переживаниями, так и для терапии эмоциональных травм, к которым можно отнести психотравму развода. По мнению П. Левина, данный метод направлен на активацию, осознание и дезактивацию телесного переживания травматического опыта. Ключ к исцелению травмы лежит в осознании и переживании того, что телесно ощущается. Суть работы психотерапевта заключается в том, что в ходе телесных ощущений происходит пробуждение тех естественных исцеляющих процессов, которые позволяют излечиться от травмы. Телесное ощущение актуализирует у человека, переживающего травму, незавершенные травматические реакции и помогает им завершиться. Это завершение происходит благодаря специфическим психологическим и физиологическим исцеляющим процессам, которые возникают в процессе телесного переживания и позволяют трансформировать травматические симптомы [4].

\section{Выво $\Delta ы$}

На основании результатов проведенного эмпирического исследования можно сделать следующие выводы.

1. В современной психологии психотравма определяется как жизненное событие или ситуация, которая, затрагивая значимые стороны существования человека, приводит его к глубокому и длительному переживанию негативных эмоциональных состояний. Среди психотравмирующих ситуаций необходимо определить особый тип психотравмы - «психотравму развода», связанную с распадом брачно-семейных отношений. Психотравма развода в отличие от психотравм, которые были обусловлены стихийными бедствиями или внезапными событиями, характеризуется длительной чередой предшествующих конфликтов, что усугубляет ее переживание.

2. Согласно рассмотренным нами научным источникам и полученным в ходе эмпирического исследования результатам, развод может и должен рассматриваться как психотравмирующее событие. Подтверждением этому является снижение позитивного и повышение негативного аффекта в эмоциональной сфере человека. Несмотря на то, что в основной группе в среднем все же преобладает позитивный аффект, сравнение с контрольной группой свидетельствует об эмоциональном неблагополучии лиц, переживших развод. В крайних своих проявлениях психотравма развода может соответствовать психотравме, связанной с утратой близкого человека.

3. Жизненная перспектива людей, переживших психологическую травму развода отличается от жизненной перспективы людей, живущих в браке. В среднем, группа респондентов, переживших развод оценивает свое прошлое как гораздо более негативное, чем контрольная группа. В оценке различных аспектов настоящего (гедонистическое и фаталистическое настоящее) у них также наблюдается сдвиг в сторону негативных оценок гедонистического настоящего с повышением роли фаталистического настоящего. Но в оценке будущего, напротив, в основной группе респондентов больше доминируют положительные оценки, что предположительно связано с психологической защитой и стремлением избавиться от психотравмы.

4. Среди различных направлений временной перспективы (прошлое, настоящее и будущее) наиболее уязвимым для влияния психотравмы оказывается прошлое, поскольку именно прошлое респонденты оценивают, как более негативное и оценки прошлого сильнее всего связаны с изменением аффективной сферы. Переживание негативного прошлого выражается в сожалении об 
утраченных возможностях, потерянном времени, переживании неудачной судьбы и т.д. и т.п. В то же время, оценки настоящего и будущего у респондентов сравнительно слабо связаны с соотношением позитивного и негативного аффекта.

5. В психотерапевтической практике искажения временной перспективы у клиента могут являться симптомами психологической травмы, даже если клиент отрицает ее наличие у себя. Восприятие своего прошлого как череды неудач, а не возможности получения жизненного опыта, восприятие настоящего как фатального и не приносящего ни- каких радостей с одновременной верой в то, что в будущем все разрешится само собой, может свидетельствовать о явном или скрытом психологическом неблагополучии личности.

6. Исследования искажения временной перспективы под влиянием психотравмы - сравнительно новое направление в прикладных психологических исследованиях. По этой причине многие аспекты данной проблемы еще слабо изучены и могут выступать предметом самостоятельного исследования.

\section{ЛИТЕРАТУРА}

1. Головаха, Е.И. Жизненные перспективы и ценностные ориентации личности [Текст]/ Е.И. Головаха // Психология личности в трудах отечественных психологов. - СПб., 2001. - 356 с

2. Деревянко, Ю.П. Особенности переживания времени в студенческом возрасте [Текст]: автореф. ... дис. канд. психол. наук / Ю.П. Деревянко. - Белгород, 2013. $-24 \mathrm{c}$.

3. Муздыбаев, К. Переживание времени в период кризисов [Текст] / К. Муздыбаев // Психологический журнал. - 2014. - Т. 1. - № 4. - С. 5-21

4. Levin P.A. Waking the Tiger-Healing Trauma. The Innate Capacity to Transform Overwhelming Experiences / Peter A. Levin with Ann Frederick. Berkeley, California: North Atlantic Books, 1997, 247 p.

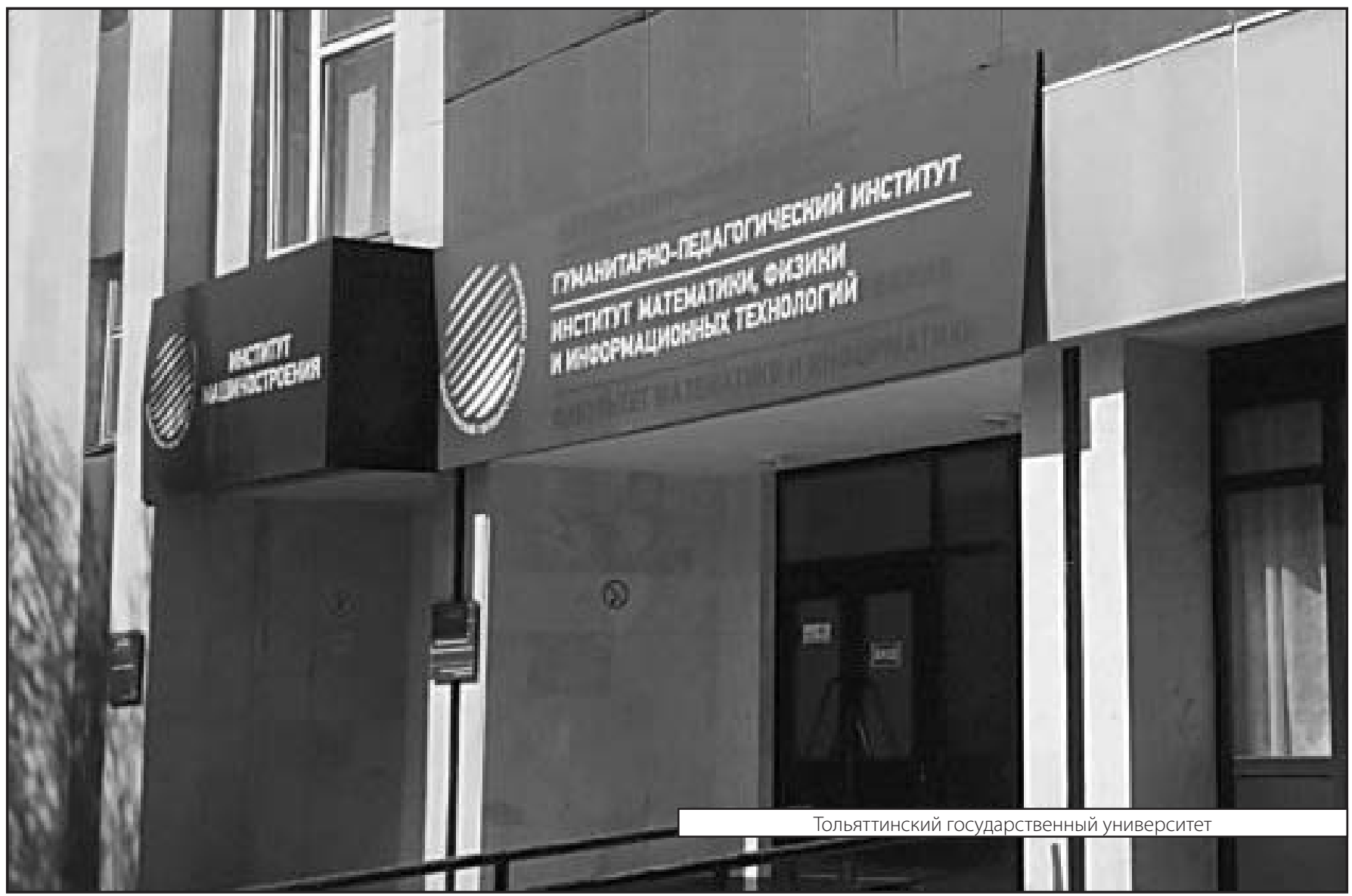

